\title{
Biorefineries - from biofuels to the chemicalization of agricultural products
}

\author{
Jacek Kijeński \\ Warsaw University of Technology - School of Engineering and Social Sciences in Ptock, Industrial Chemistry Research \\ Institute, Rydygiera 8 str., 01-793 Warszawa, e-mail: jacek.kijenski@ichp.pl
}

\begin{abstract}
The recent research into the viable economy in sustainable energy from renewable sources has prompted a review into the potentials of Polish-oriented raw material sources as a catalyst for technological advance, product diversification and consumer satisfaction. The elongation of the process chain in vegetable (rape seed, potato), alcohol additives and glycerin processing has been found to drastically improve energy balances for the short processing methods adopted presently and can make Poland self sustainable in the future.
\end{abstract}

Keywords: biorefinery, rape seed, transesterification, glycerin economy, FAME.

Presented at VII Conference Wasteless Technologies and Waste Management in Chemical Industry and Agriculture, Międzyzdroje, 12 - 15 June, 2007.

\section{INTRODUCTION}

Limited access to liquid fuels (liquid and gaseous) which are supplied mainly by refineries is the factor inhibiting the rapid growth of the global car industry. The oil raw material used in the production of liquid fuels is unevenly distributed on the earth's crust and the countries which have a difficult access to it have, for several years, been trying to develop substitutes either through the liquefaction of carbon or through the conversion of natural gases.

Current predictions indicate a maximum exploration of crude oil on earth in $20-30$ years with deposits estimated at 110 billion tones $^{1}$ and a $50 \%$ rise in demand over the next 15 years ${ }^{2}$. The demand could be much higher, taking into consideration an increase-in crude oil consumption of about $2 \%$ annually, the consumption in medium and highly developed countries will quadruple already in the first half of the XXI century. There is about a billion barrels of crude oil in „documented" reserves, about 7 billion is added annually (recently discovered reserves) and about 26 billion in use ${ }^{3}$. Part of the documented reserves could be non-existent, because it could have been declared in 1986 - 90 when the exploration quota in OPEC was dependent on the amount of reserves. Therefore, the issue of the most effective usage of the raw materials for fuelling machines has become a global issue. Apart from crude oil, natural gas is another source of raw materials (enough reserves till the end of this century unless a technology is invented to tap the methane hydrate resources beneath the ocean floor which is estimated at $0.5-2.5$ billion tons by British Petroleum) and also from coal (enough for centuries).

However, in the seventies there was a conviction that refining to conventional fuels may not be profitable, but hydrogen, which can be obtained from them, is the fuel of the future.

This is all based on efforts being made all over the world in the last twenty years to develop and introduce economically viable processes to convert raw materials from plants to liquid biofuels which can be used in spark engines as well as diesel engines. Fuels from plants can comprise an interesting alternative to oil products in the countries with an advanced agricultural system, especially laden with over-production of agricultural products designated for the consumer industry and also in the case of possessing degraded land, due to the industrial activities. Brasil (a leader in sugar cane production) has made spectacular developments in this aspect and also some technical success has been achieved in Europe in the production of biofuels based on the alcoholic fermentation of sugars and production of vegetable oils.

In Poland the issue attracted attention in the mid nineties of the last century and resulted in an unsuccessful investment - the construction of a test biorefinery in Mochełek. A revival of interest has occurred with activities in accordance with legal regulations of the EU (Directive) and first of all rightful anticipation of the agricultural lobby. This is all happening in the atmosphere of changing factors - the price of a barrel of crude oil has exceeded all pessimistic forecasts, a drastic fall in vodka consumption in the country, as a result of which many distilleries were on the verge of bankruptcy (or bankrupt), the deregulation of agric lands from agric production as a result of access to the EU, and finally tax rebates for fuels with biocomponents according to the defunct Law of Biocomponents of 2 October 2003 (Dz.U. nr 199 position 1934). The lack of competence of the participants of the national discussion, a conflict of ideas of different lobbying groups, and finally the opinion that tax preferences for producers is the major argument in the introduction of biofuels to consumption has caused that the technical issues regarding production were relegated to the background. For instance, the problem of the utilization of glycerin as a by-product in the transesteryfication of vegetable oils was not addressed at all. Up till now, only one facility has been opened to produce FAME (Fatty Acid Methyl Esters) with a capacity of over 100 thousand tons/year in Trzebinia Refinery S.A. (intended intensification to 200 thousand tons). The other potential producers of fatty acid esters as fuel biocomponents plan to produce 1 mln t (JMF, Elstar Oil, Zakłady Azotowe Puławy S.A., Polskie Młyny, Grupa Kapitałowa R. Karkosika). In addition, the fermentation sector is planning to increase the production of bioethanol.

In this presentation I attempt to justify the reason for an intensive development of biofuel (biocomponents for fuels) production in Poland. This development, however has to take into consideration the conditions (national raw material capabilities), feasibility of the processes, independent of the rapidly changing tax regulations and 
finally the influence of new generation fuels on the environment. The most important argument for the dynamic and complex development of the biofuel sector in Poland is the advantage that this development will trigger the effective utilization of Polish agriculture as a rich natural resource source. In the first half of the twentieth century, the development of the fuel industry based on crude oil led to the construction of a modern chemical industry, originating from petrochemistry - the processing of crude oil distillation by-products which are not useful as fuels. Today, the processing of oily plants for fuels is undoubtedly the wheel of progress not only in energy, but also (maybe mainly) in the chemical utilization of the byproducts of this process.

The usage of innovative technology to balance the material and energy circle in the production of biodiesel for the processing of other agricultural materials (biomasses) is already establishing a new industry sector: the chemicalization of agroproducts. A discipline in which Poland has a wonderful tradition. The third technology in the world for the production of synthetic rubber (KER Eritrence rubber) invented in the thirties of the twentieth century in the Chemical Research Institute (presently Industrial Chemistry Research Institute) and the production commenced in Dębica and further in the USA (Publicker) and Italy in the forties, was based on butadiene obtained from the fermentation ethanol. Polish tyres from potatoes as fabulously written about in Sztafeta (Relay) Melchior Wankowicz. It couldn't have been different in a country which was a leader in potato production in Europe (over $20 \mathrm{mln}$ tons in 1938).

Let us now imagine that the Polish rape seed, just as some time ago potato was for ethanol, is a sufficient raw material for the biodiesel plans of producers in Poland. The figures for the production of rape seed in Poland are presented in Table 1.

Table 1. Rape oil production in Poland

\begin{tabular}{|l|l|}
\hline Years & Production \\
\hline $1985-1990$ & $1300 \mathrm{t}$ tones/year \\
\hline $1990-1991$ & over $1 \mathrm{mln}$ tones/year \\
\hline 2001 & $1063,6 \mathrm{t}$ tones \\
\hline 2002 & $952,7 \mathrm{t}$ tones \\
\hline 2003 & $793,0 \mathrm{t}$ tones \\
\hline 2004 & $1600 \mathrm{t}$ tones \\
\hline 2005 & $1434 \mathrm{t}$ tones \\
\hline
\end{tabular}

source: Rape Oil Market. Present state and perspectives

Publishers: Institute of Agricultural Economics and Food Economy

Rape is a demanding (soil, fertilizers) and capricious (weather) plant which is evident in the huge changes in cultivation areas. The capacity of today's agriculture in Poland is 1600 thousand tons annually, of which 500 thousand tons are designated for consumption processing. This leaves about $1 \mathrm{mln}$ tons rape seed of $42 \%$ fatty content for the industry. This means that Polish raw material potential of about 420 thousand tons of oil for transesterification. This is not much compared to the indications which producers declared earlier. So we have before us the intensification of cultivation, import of grain (most probably from the East) and maybe an intensified search for another oily plant. The use of rape oil as energy carrier precursor is viable today, first of all due to legal regulations, regarding the addition of biocomponents and excise tax. The theoretical energy efficiency of rape cultivation as fuel ranges from 1.9:1 to 2.1:1 which means that more than $90 \%$ or $110 \%$ of the energy spent on cultivation and processing of the raw material is recovered $^{4}$. This is with regard to the complex processing (energetic) of all sectors of the plant and its by-products. The energy balance of combustion of rape oil fuel in a diesel engine is presented in Fig. 1.

It is easy to calculate how this balance deteriorates if the side product stream is neglected or only partially considered. The effectiveness of the whole process depends solely on the production from one hectare, which of course happens on condition that the main energy delivered comes from the sun.

The energy balance in the production of ethanol is even less advantageous. Enthusiasts in the USA claim that the energy gain in the fermentation of ethanol from corn is $40 \%$, but according to Prof. David Pimentel (Cornell University), for the production of 1 gallon of ethanol (together with the plantation and storage of corn) 131 thousand BTU (British Thermal Unit) is needed while the combustion produces only 77 thousand BTU ${ }^{6}$. Prof. Tad W. Patzek of the University of California presented even less promising calculations. According to his calculations, 1 bushel $\left(36,4 \mathrm{dm}^{3}\right)$ of corn produces 2,66 gallons $\left(10,2 \mathrm{dm}^{3}\right)$ of ethanol after fermentation of combustion values equal to 1,74 gallons $\left(6,6 \mathrm{dm}^{3}\right)$ of petrol which is $65 \%$. Morover the balance of greenhouse effect gases emitted during the production and combustion of ethanol is far less advantageous than for the methanol and crude oil derivatives.

The disadvantageous energy balance for the production and combustion of ethanol lies in the nature of alcohol fermentation which is a property of monosugars. The primary building block of the biosphere are multisugars which are not fermented by yeast, so should be hydrolised (chemically or enzymatically), and then later fermented. New raw materials whose hydrolysis is simple and cheap, such as the pirolysis of cellulose ${ }^{9}$, or the products of the steam reforming of wood are becoming more profitable.

The European Parliament directives are somehow silent on the quality of bioethanol added to fuels. The presence of ethanol could cause the phase separation of fuels and even the crystallization of water at low temperatures. Meanwhile, in Poland, 96\% alcohol is the dominant product of the alcohol industry (Polish norms require the application of the $100 \%$ product in the presence of a stabilizer). The water problem can be resolved by using surfactants which form a two-phase microemulsion system water-alcohol (or even water-vodka). The addition of emulgators, however requires prior estimation of the total combustion values, the toxicity of the added components and the combustion of the products.

Summarizing, the decision as to whether ethanol is an appropriate additive to fuels has a political motive all over the world (often with justification - the usage of overproduced agricultural products, new jobs). On the other hand, it is worth noting that the fuel crisis of the seventies caused the introduction of a better additive to fuels - methanol. Its combustion is cleaner than as compared to ethanol (as a result of thermal dissociation, we achieve the combustion of carbon dioxide and hydrogen 


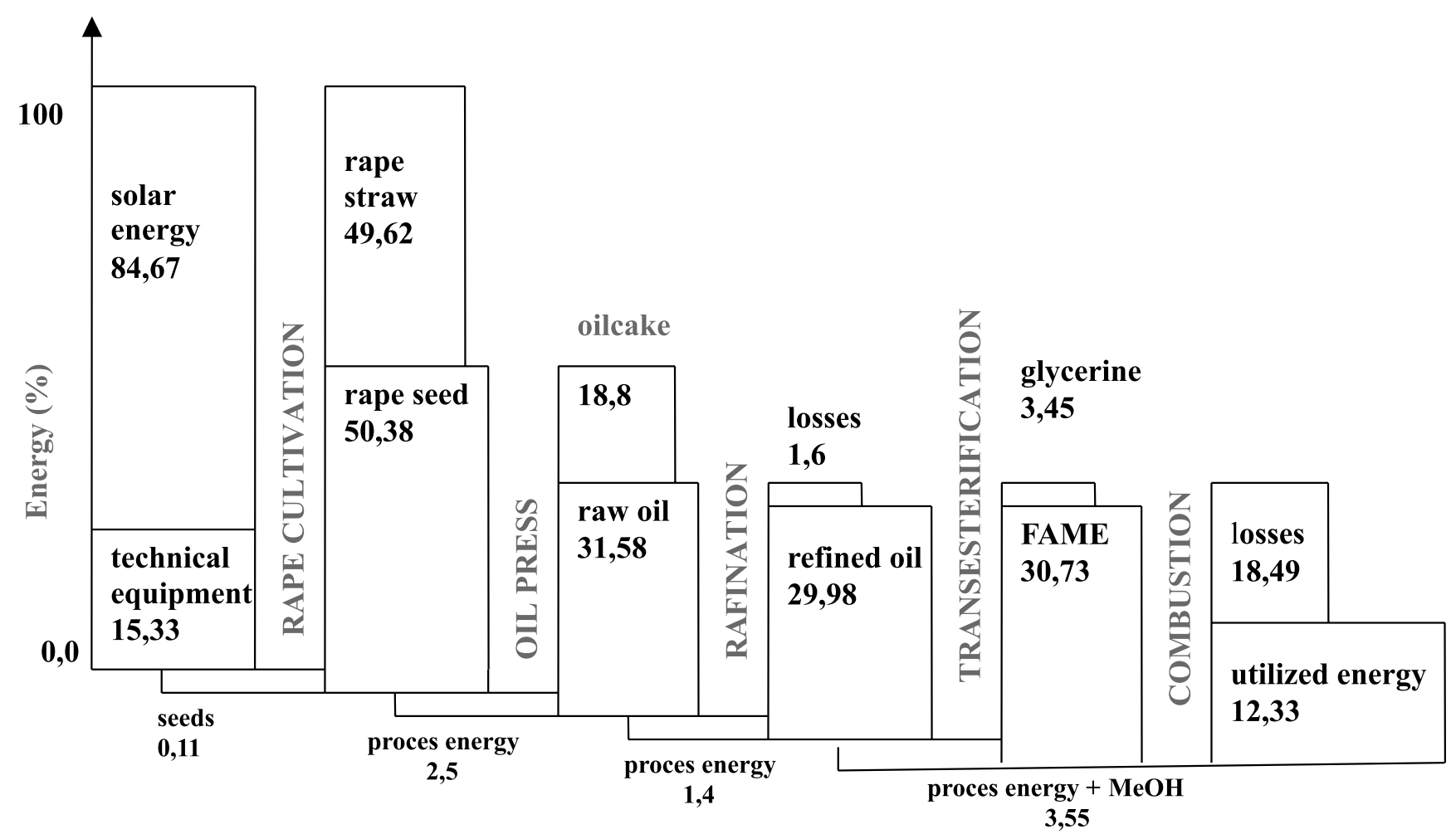

Figure 1. Combustion energy balance in diesel engine for fuels from rape (1 ha cultivation)

in the engine and not alcohol) and burns quicker (quicker than petrol fumes). It should be emphasized that modern method of methanol synthesis from biomass are close to technological perfection.

In the strategy to ensure a supply of fuels in Poland, it is also most important, that the route to the gasification of our national mineral (coal) to methanol is short and we have also recorded some global success in this direction (prof. Błasiak's catalyst from the 1940s and technology based on it). The utility properties of fatty acid methyl and ethyl esters (FAME and FAEE) as additives to diesel fuels do not evoke as much controversy as the properties of ethanol. They generally possess higher cetane numbers than the traditional diesel fuels, they lack sulphur and considerably reduce the environmental pollution from diesel engines. The biodegradability of fatty oil esters, as well as their reactivity when in contact with water and oxygen, is an important advantage (environmental protection) but at the same time a crucial disadvantage. Chemical changes resulting from the ageing of oil significantly worsens its utility properties. Partial oxidation of the fuel multiplies its susceptibility to the activity of microorganisms.

Furthermore, water contained in the vessel enhances the growth of bacteria and fungi which accelerates the degradation of the fuel, also regarded as a chemical reaction (hydrolysis). The decisively higher chemical reactivity of fatty acid esters as compared to hydrocarbons is also evident in the destructive activity on a series of polimers present in the construction elements of vehicles and also in the cover paints. This will require a modification of vehicle construction materials which come into contact with fuels possessing FAME and FAEE.

Taking into consideration the utility properties discussed above it is difficult to imagine the application of pure fractions of esters of higher fatty acids as fuel for diesel engines. Rudolf
Diesel himself probably came to the same conclusion when he applied vegetable oil (apart from wine alcohol) in the engine constructed by him at the turn of the 19th and 20th centuries. The fact that the original diesel fuel could not compete with the mineral oil fraction is of much significance. There is no doubt that, as an additive to traditional fuels, biodiesel can significantly increase the utility properties of oils (combustion, greasing, low sulphur level etc.). In the case of a limited quantity of fatty acid esters, the chemical reactivity and biochemical susceptibility will not be so dangerous for the utility properties of fuel. Let's return to the biorefinery conception. Its earlier indicated, positive economic effect (without tax regulations) is dependent on the energy/material balance within the cultivation and processing of the plant. The chemical processing chain of the leftovers that are not worth burning to products should lead to a high added value for as much as possible.

This can be illustrated on the basis of glycerin which is the main by-product (over $8 \%$ weight) in the transesterification of rape oil. Up till now glycerin has been used after a costly purification process as a valuable raw material in cosmetics production, consumer goods and also as an additive to toothpastes and chewing gum.

The applications of glycerin to date do not require production leading to FAME or FAEE (over 8000 tons for every 100000 tons of produced bio-fuel). There are two methods to utilize excess glycerin. The shorter, for the short term, is to burn the glycerin to produce electrical energy which will allow the usage of the much higher prices of green energy (presently 15 PLN for $1 \mathrm{GJ}$ ). The advantage of this route will, however be dependent on respective legal regulations. The second strategic route is to develop a glycerin product tree. An implementation tree of a broader added value chain which simultaneously guarantees a wide diversification of the products. An example of an attractive branch of this tree is being devel- 
oped at the Prof. I. Mościcki memorial Industrial Chemistry Research Institute a technology to obtain akrilanes in the chain glycerin $\rightarrow$ acrolein $\rightarrow$ acrylic acid $\rightarrow$ acrylic acid esters which are presently not available in Poland. There is still a third solution making glycerin a component of biofuels. This is the case with gliperol $\AA$, a biofiuel developed in our Institute ${ }^{\mathbf{1 2}}$. Gliperol is obtained as a product of cross-transesterification in which rape oil is esterified with methyl or ethyl acetate. The obtained FAME together with the formed triacetine glycerin constitute a biofuel whose utility properties exceed those of traditional ester mixtures and the process is entirely waste-free. This method has been awarded several gold medals in international and worldwide inventors fairs and its modification can allow the application as biofuel of other vegetable oils such as palm oil and also animal fat, including wastes such as the expired butter.

The complex processing of rape oil in a biorefinery consists of the utilization of all parts of the plant, chemical, energy and probably also as feed (limited application due to the presence of lucozames). There is also the extraction from FAME of a series of chemical compounds (eg. sitosterols, much demanded for in pharmacy) which are too valuable to be burned in an engine before its application as a bioadditive.

The realization of biorefinery concept requires a complex development plan:

- a technology to chemically and energetically utilize raw materials from rape oil such as straw, oilcake, bruised grain (the case of the fermentation processing of corn - the stalk, chaff, cob and leaves),

- a technology for the effective and profitable disintegration of cellulose, hemicelluloses and lignin,

- technology for the utilization of plant and animal proteins,

- catalytic (enzymatic, microbiological and classical) methods for the conversion of carbohydrates, vegetable oils and animal fat into chemicals,

- the technology to process diluted waste streams in order to recover chemicals from them.

The purpose of a biorefinery activity is to obtain biofuels, valuable organic compound and new materials.

\section{LITERATURE CITED}

(1) IPCC Working Group III IPPC 3rd Assessment Report. Climate Change 2001: Mitigation.Summary for Policymakers, http://www.ipcc.ch/wg3spm.pdf.

(2) Sandrea I.: Al Buraiki, Oil and Gas Journal, 100 (24) 22 (2002).

(3) Hughes J.R.: Oil \& Gas Journal, 97 (46) 8(1999).

(4) Portrait E.: Europ. J. Lipid Sci. Technol., 104 (6) 369(2002).

(5) Morris D.: Los Angeles Times, Feb. 15, 2004.

(6) Hydrocarbon Processing, 81 (7) 11(2002); Manjoo F.: Wired News, Aug. 14, 2001.

(7) Young S.: UC, Berkeley News, June, 5, 2003, http:// 128.143.109/papers/patzet,Ethanolfromcorn.htm.

(8) Nakamura D.N.: Hydrocarbon Processing, 75 (10)15 (1996).

(9) Yu Z., Zhang H., Biomass \& Bioergy, 24 (3) 257 (2003).

(10) De Bari I., Viola E., Barisano D., Cardinale M., Nanna F., Zimbardi F., Cardinale G., Braccio G., Ind. Eng. Chem. Res. 41 (7) 1745(2002).
(11) Notified Pat. P-379283 of. 24.03.2006 r.: Kijeński J., Migdał A., Osawaru O., Śmigiera E.: Methods of processing of glycerin fraction obtained in the transesterification of fatty acid triglicerides.

(12) Notified Pat. P-359907 z 2003 r., Kijeński J., Lipkowski A., Walisiewicz-Niedbalska W., Gwardiak H., Różyczki K., Pawlak I.: Metod of synthesis of biofuels for diesel engines.

(13) Notified European Pat. from 19.05.2004 r., Kijeński J., Lipkowski A., Walisiewicz-Niedbalska W., Gwardiak H., Różyczki K., Pawlak I.: A biofuel for compression-ignition engines and a metod for preparing the biofuel for compression-ignition engines.

(14) Notified Pat. P-378098 z dn. 16.12.2005 r., Lipkowski A.W., Kijeński J., Walisiewicz-Niedbalska W., Różyczki K., Pawlak I.: New biofuel component and method of synthesis of new biofuel components. 